\title{
Acquired angioedema type 2
}

INSERM

\section{Source}

INSERM. (1999). Orphanet: an online rare disease and orphan drug data base. Acquired angioedema type 2. ORPHA:100055

Acquired ang ioedema type 2 (AAE2) is a type of acquired angioedema (AAE, see this term) characterized by acute edema in subcutaneous tissues, viscera and/or the upper airway. 